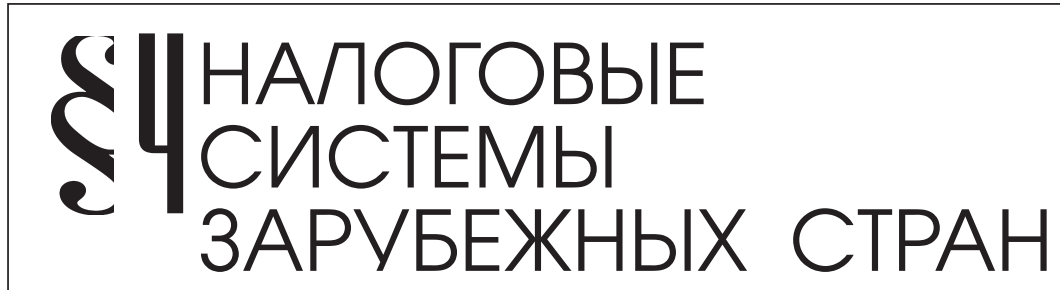

Иманшапиева М. М., Мусаева Х. М.

\title{
СИСТЕМЫ НАЛОГООБЛОЖЕНИЯ СУБЪЕКТОВ МАЛОГО БИЗНЕСА: ОПЫТ ИНДУСТРИАЛЬНЫХ СТРАН И ВОЗМОЖНОСТИ ЕГО ИСПОЛЬЗОВАНИЯ в УслОВИЯХ РФ
}

Аннотация. В настоящей статье рассматриваются системы налогообложения субъектов малого бизнеса, используемые в зарубежной практике. Раскрываются прогрессивные элементы налогового регулирования и поддержки малого бизнеса экономик индустриальных стран, с точки зрения возможностей использования в экономике РФ. Особое место уделено специиальным режимам налогообложения, а также налоговым методам стимулирования инновационной активности субъектов малого бизнеса. На основе изучения, анализа и обобщения зарубежного опыта налогообложения мальх фирм в статье обоснован комплекс научно - практических рекомендаций по совершенствованию системы налогового регулирования и поддержки малого предпринимательства в условиях России.

Ключевые слова: налоги и налогообложение, экономика, мальй бизнес, перспективы, льготы, ставки, стимулирование, разработки, инновация, поддержка.

Review: The present article is devoted to studying the systems of taxation of small business entities used in the foreign states. The authors of the article describe progressive elements of tax regulation and support of small business in industrial countries and analyze them in terms of their feasibility for the Russian Federation economy. Special attention is paid to particular taxation schemes as well as taxation methods of stimulating innovative activity in small business. Based on studying, analyzing and summarizing foreign experience in taxation of small entities, the authors of the article provide a number of scientific and practical recommendations on how to improve the system of tax regulation and support small entrepreneurship considering the conditions and peculiarities of Russian economy.

Keywords: taxes and taxation, economics, small business, prospects, privileges, rates, stimulation, development, innovation, support. 
B современных условиях РФ переход к инновационному развитию экономики и ее модернизация являются одним из ключевых факторов активизации экономического роста. Внедрение основанных на достижениях научно-технического прогресса новых, передовых технологий, форм организации труда и управления особенно актуально в сфере малого бизнеса, поскольку именно малые предприятия выступают в качестве связующего звена между наукой и производством. Роль малого бизнеса в основных параметрах развития нашей страны значительно ниже, по сравнению с индустриальными странами. Так, по числу малых предприятий Россия ${ }^{1}$ отстает от США — в 93 раза, от Японии — в 7,7 раза, от Италии - в 4,7 раза; по доли вклада малых предприятий в ВВП от Франции в 5,6 раза, от США — в 4,7 раза, по доли занятых в малом бизнесе отличается в меньшую сторону от Японии в 8,1 раза, от Италии в 7,6 раза, от США и Франции в 5,6 раза².

Выше изложенное позволяет утверждать, что в России государственная поддержка малого бизнеса осуществляется не всегда целенаправленно и потому недостаточно эффективна. На пути экономического развития малого бизнеса в России имеется множество проблем как финансово- экономического, так организационного характера, которые могут быть решения посредством эффективного использования всей гаммы инструментов государственного регулирования, в том числе и с помощью налоговой политики. В этой связи в условиях РФ, чрезвычайно интересным и полезным представляется изучение опыта налогообложения субъектов малого бизнеса развитых зарубежных стран. На современном

\footnotetext{
1 Данные официального сайта Общероссийской общественной организации «Опора России» www. opora. ru.

${ }^{2}$ Мельник А. М. Малый бизнес и региональное развитие в индустриальных странах.- М., 2007.- С.123
}

этапе повышение роли предприятий малого бизнеса в индустриальных странах — не случайность, а необходимая закономерность, вызванная самим ходом истории, и потребностями, которые возникали в процессе развития научно- технического прогресса.

Важным аспектом налогообложения малого бизнеса является критерий признания предприятия малым. Несмотря на то, что в развитых странах общих принципов определения такого критерия не существует, и они широко варьируются между странами. Основными критериями отнесения предприятий к малым являются объем хозяйственного оборота и численность работников. Так, во Франции к малым относятся фирмы с числом занятых от 10 до 50 чел., при этом совокупный годовой оборот предприятия не должен превышать 3,5 млн. франков для фирм, реализующих товары, и в пределах 1 млн. для производителей услуг ${ }^{3}$. В Великобритании, к разряду мелких относят фирмы с числом занятых до 24 чел., а также предприятия с годовым оборотом не более 400 млн. фунтов стерлингов (это 96\% общего числа частных компаний) ${ }^{4}$. В США, к категории малых относят предприятия с числом занятых до 500 чел., годовым доходом от 3 до 12 млн. долл. и величиной активов не более 5 млн. долл. (подобные фирмы составляют 99\% всех американских компаний $)^{5}$

Специфика малого бизнеса (социальная значимость и массовость) определила особенности его налогообложения в индустриальных странах, которое ориентировано на долгосрочные цели экономического разви-

\footnotetext{
${ }^{3}$ Грибкова Н.Б. Опыт налогового регулирования в зарубежных странах и возможности его использования в России. //Налоговая политика и практика. 2005.№ 7.- С.16

${ }^{4}$ Explanatory Notes to the OECD Tax Database, 2005. www. oecd.org/dataoecd

${ }^{5}$ Мельник А. М. Малый бизнес и региональное развитие в индустриальных странах.- М., 2007.- С.18
} 
DOI: $10.7256 / 1812-8688.2013 .12 .4059$

При цитировании этой статьи сноска на dоі обязательна

\section{Налоги и налогообложение - №12(114) • 2013}

Таблица 1

Критерии отнесения предприятий к субъектам малого предпринимательства в зарубежных странах

\begin{tabular}{|c|c|c|}
\hline Страны & $\begin{array}{c}\text { Численность работников, } \\
\text { не более }\end{array}$ & $\begin{array}{c}\text { Годовой оборот, } \\
\text { не свыше }\end{array}$ \\
\hline Великобритания & $\begin{array}{c}\text { 24-99 чел. (до } 250 \text { чел. в про- } \\
\text { мышленности) }\end{array}$ & 400 тыс. фунтов стерлингов \\
\hline Бельгия & 100 чел. & 145 млн. бельг. франков \\
\hline Франция & 200 чел. & 3,5 млн. франков \\
\hline Германия & 500 чел. & до 11,5 млн. евро \\
\hline Люксембург & 100 чел. & 60 тыс. люкс. франков \\
\hline Япония & $\begin{array}{c}100 \text { (не свыше } 300 \text { в промыш- } \\
\text { ленности) }\end{array}$ & $\begin{array}{c}30 \text { млн. иен (до } 100 \text { млн. в промышлен- } \\
\text { ности) }\end{array}$ \\
\hline США & 500 чел. & 3-12 млн. долл. \\
\hline Канада & 100 чел. & 2-20 млн. долл. \\
\hline Китай & 100 чел. & 300 тыс. юаней жэньминьби \\
\hline
\end{tabular}

Составлено автором по: 1.Мальй бизнес и региональное развитие в индустриальных странах.— М., 2007 -

C.18-20; 2. Explanatory Notes to the OECD Tax Database, 2005. www.oecd.org/dataoecd

тия и привязано к реально складывающимся экономическим пропорциям внутри данного сектора. В различных странах при использовании специальных режимов налогообложения преследуются разные цели. Также различны обстоятельства, сопутствующие такому налогообложению, налоговая и юридическая грамотность налогоплательщиков, отличаются возможности контроля и принуждения со стороны налоговых администраций и степень коррумпированности властей. Все это определяет многообразие подходов к налогообложению малого бизнеса.

Фактически режимы налогообложения субъектов малого предпринимательства, в достаточной степени, различны в зависимости от страны, целей и условий в которых они применяются. Из-за этих больших отличий в системе налогообложения развитых стран абсолютные числовые показатели в ряде стран вообще не сопоставимы, и выделить общие черты достаточно сложно.

Малое предпринимательство стран ЕС и США также использует несколько систем налогообложения. Это специальные налоговые режимы (обусловленные приоритетами национальной экономической политикой), общий режим (налог на прибыль корпораций) и подоходный налог для частных предпринимателей. Но из-за не тождественности понятий малого предпринимательства сравнивать налоговую роль малого предпринимательства России и зарубежных стран некорректно.

Отметим, одной из наиболее существенных прямых льгот для малого бизнеса в развитых странах является снижение ставки по налогу на прибыль. Специфика данной льготы состоит в том, что случаи, когда уменьшение ставки прямо объявляется налоговой льготой, достаточно редки. Обычно более низкие ставки налога на прибыль вводятся в качестве 
самостоятельного направления налоговой политики, за рамками установления налоговых льгот.

Пониженные ставки для предприятий, относящихся к малому и среднему предпринимательству, применяются в Бельгии, Канаде, Финляндии, Японии, Люксембурге и Великобритании. Помимо этого, как отдельные меры стимулирования в отношении малого предпринимательства могут применяться менее строгие требования по ведению налогового и бухгалтерского учета, а также может быть заметно упрощен порядок предоставления различной отчетности.

Изучение опыта индустриальных стран в области налогового регулирования деятельности субъектов малого бизнеса показало, что одним из основных налоговых стимулов способствующих развитию малых предприятий в развитых странах является применение в рамках общеустановленной налоговой системы прогрессивных ставок налогообложения. Прогрессивная шкала налогообложения позволяет малым фирмам в период своего становления использовать минимальные ставки налога на прибыль. В дальнейшем, постепенно увеличив объемы производства, такие компании переходят на более высокие ставки, при этом, чтобы предприниматели не были заинтересованы в искусственном сдерживании развития предприятий, наивысшая ставка налога на прибыль, как правило, несколько ниже предыдущей. Примером данного подхода является прогрессивное налогообложение прибыли предприятий в Бельгии.

В отличие от западных стран, в России не предусмотрена прогрессивная шкала налогообложения, что отрицательно сказывается на деятельности малых предприятий. Кроме того, в РФ более низкий уровень налоговой культуры, в этой связи дополнительные льготы и снижение ставок, в рамках упрощенного режима налогообложения не приводят к же- лаемому эффекту (расширению налогооблагаемой базы и росту налоговых поступлений).

Важную роль в стимулировании экономической активности субъектов малого бизнеса посредством налоговой политики играет подоходный налог. В подавляющем большинстве развитых стран используются прогрессивные ставки подоходного налога, и верхние значения этих ставок могут достигать 59\% (в Швеции и Швейцарии) и даже $63 \%$ - в Дании. Но при этом для тех, кто занят частным бизнесом, введен особый необлагаемый минимум (в Великобритании - 4895 фунтов стерлингов) или применяется тот же, что и для физических лиц ${ }^{1}$.

Отметим, что для физических лиц необлагаемый минимум в Европе, существенно выше российского: в среднем - 6200 евро в год (в России - 160,4 евро) $)^{2}$ В Австрии и Германии существенная доля малых фирм не имеет статуса юридического лица, т.е. организованы в форме частных предпринимательств и партнерств. В этой связи, подоходный налог является основным налогом, при этом необлагаемый минимум составляет 15770 евро для наемных лиц и 10000 евро для индивидуальных предпринимателей.

Значительные льготы по подоходному налогу имеют также индивидуальные инвесторы в США, вкладывающих средства в малый инновационный бизнес, в отличие от России. Также необходимо отметить, что в индустриальных странах, несмотря на сокращение льгот и их оптимизацию, сохранены льготы стимулирующие образование новых акционерных обществ в наукоемких отраслях.

\footnotetext{
1 Structures of the Taxation Systems in the European Union, Data 1995-2005 / Theme Economy and Finance.European Commission Edition, 2007.— PP.146

2 Акимов А.А. Анализ практики налогообложения малого бизнеса в России. // Все для бухгалтера. 2007.№ 4- C. 24
} 
DOI: $10.7256 / 1812-8688.2013 .12 .4059$

При цитировании этой статьи сноска на dоі обязательна

\section{Налоги и налогообложение - №12(114) • 2013}

Таблица 2

Сравнительная характеристика показателей развития малых инновационных предприятий (МИП)

в развитых странах и России

\begin{tabular}{|c|c|c|}
\hline Показатели & $\begin{array}{c}\text { В развитых } \\
\text { странах } \\
\text { России }\end{array}$ & 80 \\
\hline Доля МИП среди малых предприятий, $\%$ & 30 & 5 \\
\hline Объём научных исследований и разработок МИП, $\%$ & 20 & 2 \\
\hline Объем всех создаваемых новшеств, $\%$ & 15 & 2 \\
\hline Доля МИП в обрабатывающей промышленности, $\%$ & 60 & 3 \\
\hline
\end{tabular}

Составлено автором по: 1. Данные официального сайта Общероссийской общественной организации «Опора России» www. орога. rи.; 2. Мельник А. М. Мальй бизнес и региональное развитие в индустриальных странах.M., 2007.- C.48.

Например, во Франции малые инновационные предприятия в течение первых двух лет работы полностью освобождаются от уплаты подоходного налога, на третий - облагаются $25 \%$ их дохода, на четвертый - 50\% дохода, на пятый - 75\%, начиная с шестого года, они платят подоходный налог полностью ${ }^{1}$.

Для безработных, решивших создать собственный бизнес, предусмотрено право на освобождение от подоходного налога не на два, а на три года и на год от уплаты обязательных социальных платежей. На наш взгляд подобные меры стимулирования малого бизнеса весьма успешно могут быть применены и в России в современных условиях ее развития, в особенности в трудоизбыточных регионах.

Особое внимание в развитых странах, в отличие от России уделяется развитию малых инновационных предприятий. Осуществление активной инновационной деятельности в сфере малого бизнеса в РФ,

${ }^{1}$ Мусаева Х. М. Налоговые системы зарубежных стран. Махачкала: ИПЦ ДГУ, 2011.—C.45 сдерживается рядом объективных и субъективных факторов. Выделим основные факторы, сдерживающие внедрение инноваций: отсутствие закона, регулирующего инновационную деятельность малых предприятий в РФ; недостаточная финансовая поддержка со стороны государства; высокая стоимость нововведений; низкий платежеспособный спрос на новые продукты; высокий экономический риск и длительные сроки окупаемости нововведений; низкая востребованность малого инновационного бизнеса; трудности с получением банковских кредитов; сложности с получением помещений и высокая арендная ставка; нехватка квалифицированных кадров-менеджеров и бухгалтеров, а также отсутствие действенных налоговых стимулов инновационной деятельности.

Обозначенные выше факторы и многие другие причины не позволяют малому инновационному бизнесу в России развиваться эффективно и как следствие крайне низкий уровень объема научных исследований и разработок. Так, по данным международной организации экономического сотрудничества 
и развития $(\mathrm{Э} С \mathrm{C})$, в настоящее время на долю малых инновационных фирм в промышленно развитых странах приходится до $30 \%$ объёма научных исследований и разработок, до $20 \%$ всех создаваемых новшеств. При этом, доля расходов малых инновационных фирм на нововведения составляет лишь 4-5\%. В обрабатывающей промышленности в РФ доля малых предприятий в затратах фирм на НИОКР составляет около $2,1 \%$, тогда как в экономически развитых странах - США, Германии, Италии - 5\%, Канаде, Великобритании, Испании, Финляндии - до $15 \%{ }^{1}$.

Проводимая в РФ политика в области регулирования малого бизнеса не обеспечивает необходимой поддержки и приоритетного развития малого инновационного бизнеса в стране, и как следствие удельный вес инновационных предприятий составляет менее $6 \%$ в этом секторе, в то время как малый бизнес в сфере торговли и услуг превышает $80 \%{ }^{2}$ (см.: табл. 2).

На современном этапе практически во всех развитых индустриальных странах, существует система налогового стимулирования инновационной деятельности малых компаний. Так, во Франции, действует временное освобождение от уплаты налога на прибыль или частичное его снижение («налоговые каникулы») и распространяется на вновь созданные мелкие и средние научноисследовательские фирмы

В Великобритании для стартующих инновационных компаний налог на прибыль снижен с 20\% до 1\%. Потолок не облагаемых налогом инвестиций таких компаний увеличен на 50\% — до 150 тыс. фунтов стер-

\footnotetext{
${ }^{1}$ Борисов В. Нам нужен активный, конкурентоспособный малый бизнес // Человек и труд.- 2008.— № 3.C.45.

${ }^{2}$ Малый бизнес: учебное пособие / кол. авторов: под ред. В. Я. Горфинкеля.— М.: КНОРУС, 2009.— С. 236
}

лингов. Снижен налог на прирост капитала от долгосрочных инвестиций в стартующие инновационные компании и снят налог при реинвестировании в такие компании. Действующие налоговые льготы для малого и среднего бизнеса, позволяют снижать налогооблагаемый доход на 20\% в случае, если превышен предыдущий максимальный уровень расходов на НИОКР, либо уменьшать налоговые выплаты на 6\% от величины расходов на исследования и разработки ${ }^{3}$. Расходы, которые фирмы несут при платежах исследовательским учреждениям в связи с научно-технологическим развитием, также могут вычитаться из налогооблагаемой прибыли.

В целях активизации инновационной активности за рубежом государство нередко стимулирует и подготовку кадров. Так, во Франции 25\% прироста расходов на подготовку кадров освобождаются от налогов (там, где безработица достигает больших размеров, эти затраты полностью освобождены от налогообложения).

Наиболее яркий пример успешной инновационной политики, особенно в целях развития малого и среднего бизнеса, демонстрирует Китай. Высокая степень правового обеспечения в сфере передачи технологий; налоговая система, освобождающая малые предприятия, занимающиеся освоением новых технологий, от налога на прибыль; система их льготного кредитования и финансовой поддержки обеспечили эффективное использование научнотехнического потенциала и высокую прибыль от инновационной деятельности ${ }^{4}$.

\footnotetext{
${ }^{3}$ Грибкова Н.Б. Опыт налогового регулирования в зарубежных странах и возможности его использования в России. //Налоговая политика и практика. 2005.№ 7.- С. 17

${ }^{4}$ Мусаева Х. М. Налоговые системы зарубежных стран. Махачкала: ИПЦ ДГУ, 2011.—C.142
} 
Позитивный опыт выше приведенных индустриальных стран свидетельствует, что большое значение имеет активная структурная политика - постоянно возобновляемый и осуществляемый процесс, немыслимый без активного государственного регулирования, которое должно и может содействовать оптимальному развитию и функционированию малых инновационных предприятий.

На наш взгляд, для стимулирования инновационной активности субъектов малого бизнеса РФ важная роль должна принадлежать одному из основных инструментов государственного регулирования - налогам. Для расширения объемов налогового регулирования инвестиционной и инновационной активности субъектов малого бизнеса необходимо реализовать комплекс мер по совершенствованию налогового законодательства, в частности:

- сокращение налоговых льгот и вычетов, не имеющих социальной направленности и не связанных с научной и инновационной деятельностью, привлечение к уплате налогов организаций, работающих с неучтенными денежными оборотами;

- с учетом опыта индустриальных стран, целесообразно устранение налогообложения сверхнормативных затрат на подготовку кадров для малых инновационных предприятий и в первую очередь на подготовку менеджеров инновационной направленности;

- освобождение от налогообложения дохода (в случае применения упрощенной системы налогообложения) и прибыли малых инновационных предприятий, экспортирующих не менее 50\% товаров, изготовленных с использованием российской интеллектуальной собственности (на период возврата инвестиций);

- освобождение от налогообложения дохода (в случае применения упрощенной системы налогообложения) и прибыли малых инновационных предприятий при условии выпуска импортнозаменяющей продукции и реализации ее внутри РФ. Как было отмечено выше, к примеру, в Великобритании для стартующих инновационных компаний ставка налога на прибыль снижена с 20\% до 1\%.

- принятие к учету в составе расходов индивидуального предпринимателя, уменьшающих налоговую базу по налогу на доходы физических лиц, затрат на приобретение в собственность земельного участка, на котором расположены строения, используемые для осуществления инновационной деятельности.

Система финансирования инвестиций в малое предпринимательство в инновационной сфере должна включать установление аналогичных льгот на капитал, вложенный в малые инновационные предприятия, в рамках привлечения инвестиций для стимулирования технических разработок инновационного характера, и делающих выгодным для крупного и среднего бизнеса сотрудничество с малым бизнесом. Существующие в государственной политике по отношению к малому предпринимательству в инновационной сфере противоречия (стремление наряду с поддержкой малого предпринимательства сэкономить на малых фирмах в результате отмены льгот) можно разрешить, закрепив дифференцированный подход к малым предприятиям различных типов - в частности, оказывая поддержку в первую очередь для малых инновационных предприятий.

Значительный интерес в условиях инновационного развития экономики РФ может представлять зарубежный опыт стимулирования экономической активности субъектов малого бизнеса посредством амортизационной политики. В высокоразвитых странах широко применяется ускоренная 
DOI: $10.7256 / 1812-8688.2013 .12 .4059$

При цитировании этой статьи сноска на doi обязательна

Налоговые системы зарубежных стран

амортизация оборудования как стимул для обновления производственных фондов. Они используются для стимулирования опережающего развития конкретных отраслей, поощрения НИОКР или для общего инвестиционного оживления. Так, в США установлен срок амортизации в 5 лет для оборудования и приборов, используемых для НИОКР, со сроком службы от 4 до 10 лет․ Компаниям в Великобритании разрешено списание полной стоимости технического оборудования в 1-й год его работы. В Германии в 1-й год может быть списано 40\% расходов на приобретение оборудования и приборов, используемых для проведения НИОКР. Система амортизационных списаний в Швеции позволяет оборудование со сроком службы до 3-х лет и с незначительной ценностью списывать в расходы в год приобретения, а машины и оборудование - в течение 4-5 лет. Во Франции, Японии существует возможность применения ускоренной амортизации к важнейшим видам оборудования: энергосберегающему, экологическому, информационному. Применяются разнообразные нормы ускоренной амортизации - от 10 до 50\%. Однако наиболее распространенная ставка составляет в среднем $15-18 \%{ }^{2}$.

Рассмотрим, специальные налоговые режимы используются в международной практике, их специфика и уровень налогового бремени в сравнении с российскими специальными режимами. Поскольку ряд государств оказывает комплексную поддержку малому бизнесу, используются несколько вариантов налогообложения (как и в России), то произвести их деление можно лишь достаточно условно.

\footnotetext{
${ }^{1}$ Михайлов Е. Система местного налогообложения США. США: ЭПИ; 2005.- С. 112

${ }^{2}$ Мельник А. М. Малый бизнес и региональное развитие в индустриальных странах.- М., 2007.- С.17
}

В таких индустриальных странах как Австрия, Великобритания, Венгрия, Греция, Испания, Канада, Мальта, Мексика, Норвегия, Португалия, Словения, США, Франция, Чехия для определенных видов деятельности, осуществляемых преимущественно малыми предприятиями, предусмотрены налоговые льготы или специальные режимы налогообложения. Таким образом, они стремятся поддержать отдельные виды деятельности, приоритетные с точки зрения национальных интересов, осуществляемые преимущественно малыми фирмами. В Греции налог по специальным режимам взимается с валовых доходов от указанных видов деятельности по ставке 20\% (прибыль от осуществления проектных работ облагается по ставке $16,45 \%)$. Кроме того, в Греции в отличие от России применяются несколько схем для исчисления НДС, в частности:

1. НДС не уплачивают те микропредприятия, которые не обязаны вести бухгалтерский учет, оформлять квитанции для розничной торговли, если в течение предыдущего года их валовой доход не превышал: 9000 евро по торговым операциям; 4000 евро — для фирм, предоставляющих услуги; 9000 евро для смешанных фирм (товары и услуги) при условии, что доход от услуг не превышает 4000 евро. Освобождением от НДС не могут пользоваться те, кто впервые организует бизнес; получает $60 \%$ или больше их валового дохода от оптовой продажи; переведен на специальную ставку НДС для фермеров и т. д.

2. Малые предприятия, применяющие обычную систему уплаты НДС по базовой ставке 19\%, при этом несущие значительные административные затраты, могут перейти на систему единовременно выплачиваемой суммы, согласно которой их обязательство относительно НДС состоит в том, чтобы ежегодно вносить определенный фиксированный 


\section{Налоги и налогообложение - №12(114) • 2013}

платеж. Право вычитать входящий налог в таком случае исключено.

3. Специальная система для малого бизнеса (альтернатива НДС) разработана с тем, чтобы облегчить участь малых предприятий, применяющих метод исчисления их валового дохода на основе закупочных цен и определенной нормы прибыли. Фактически они уплачивают налог с оборота ${ }^{1}$.

Следует отметить, что в международной практике НДС уплачивается практически всеми предприятиями независимо от их статуса. Там, где единый налог (в рамках упрощенной системы налогообложения) или небольшая величина доходов (оборота) допускают освобождение от обязанности исчислять и уплачивать НДС, практикуется добровольная регистрация в качестве плательщика этого налога, и для таких фирм предусматриваются определенные льготы (Великобритания). В других странах для приоритетных сфер деятельности используются сокращенные ставки НДС, в отличие от России.

В налоговой практике развитых стран гораздо чаще применяется упрощенное налогообложение. Упрощенный режим налогообложения, направлен в первую очередь на стимулирование развития деятельности субъектов малого предпринимательства. В соответствии с этим режимом индивидуальные предприниматели могут быть освобождены от уплаты некоторых видов налогов (наиболее часто в международной практике таким налогом является НДС). Также возможна замена уплаты совокупности нескольких налогов уплатой единого налога. Но в таком случае применяются различные косвенные методы определения налоговых обязательств налогоплательщика. Данный режим предусматривает комплекс мер, направленных

\footnotetext{
${ }^{1}$ Explanatory Notes to the OECD Tax Database, 2005. www. oecd.org/dataoecd
}

на принципиальное упрощение порядка расчетов и взимания налогов, уплачиваемых данной категорией налогоплательщиков.

Выбор базы налогообложения зависит от того, какие налоги предполагается заменить налогом на малый бизнес, а также от трудностей администрирования. База потока наличности является лучшей заменяющей базы налога на прибыль, а использование валовой выручки в качестве базы налогообложения целесообразно только в тех случаях, когда преобладают вопросы эффективности налогового администрирования.

Другим видом специального режима налогообложения являются вмененные налоги. Вмененные налоги в некоторых странах практически полностью отсутствуют, как в США, а других странах применяются весьма широко. Так во Франции применяется особый вмененный режим налогообложения малого бизнеса, для предприятий с совокупным годовым оборотом, не превышающим определенного порога (3,5 млн. фр. для предприятий, продающих товары, и 1 млн. фр. для предприятий, оказывающих услуги) применяется контрактный налог, или forfait ${ }^{2}$.

Отметим, что в различных странах для целей налогообложения малого бизнеса применяется множество вмененных методов. Но в международной практике (в отличие от упрощенной системы налогообложения) точного аналога российской системе налогообложения в виде единого налога на вмененный доход нет.

Среди вмененных методов, применяются специально приспособленные с учетом особенностей отдельных отраслей. Например, в Италии, используется вмененный налог, дифференцированный по видам деятельности, т.е. на основе профессии или занятия инди-

\footnotetext{
${ }^{2}$ Александров И. М. Налоговые системы России и зарубежных стран.— М.; 2007.- С.25
} 
видуума. Поскольку такое налогообложение может привести к несправедливости по отношению к некоторым налогоплательщикам, при высоких значениях сумм налога, вменяемые суммы должны устанавливаться на относительно низком уровне. В силу этого они неэффективны при обложении специалистов с высоким доходом.

Основным недостатком вмененных методов налогообложения является повышенная сложность расчета и экономического обоснования суммы вмененного дохода, устанавливаемой государством, в частности в необходимости установления отдельных значений вмененного дохода для достаточно мелких групп налогоплательщиков, что подразумевает под собой расчет и экономическое обоснование по каждой отдельной группе. Однако основными принципами, используемых в индустриальных странах специальных режимов для определенных видов деятельности является максимальное соответствие налогового бремени фактической доходности бизнеса и отсутствие дискриминирующих положений.

Необходимо отметить, что, несмотря на то, что в ряде стран как Греция, Мальта, Мексика действуют особые ставки налога с валового дохода, основным критерием выступает не размер получаемых доходов, а приоритетные для государства отрасли. Поэтому сравнить их налоговую нагрузку с российскими предприятиями (применяющими УСН со ставкой 5\% с валовой выручки или систему ЕНВД со ставкой $15 \%$ с вмененного дохода) не представляется возможным.

Итак, анализируя предпосылки формирования сильного малого бизнеса в зарубежной практике, следует отметить, что на наш взгляд, секрет высокой значимости этого сектора в экономике развитых стран заключается в эффективной и продуктивной государственной политике, направленной на развитие и поддержку малого предпринимательства.
Налоговые льготы и специальные режимы помогают окрепнуть, занять свое место на рынке, развиться малым предприятиям до уровня средних и стать полноценными участниками налоговых отношений.

На современном этапе существующие диспропорции и социально- экономическая дифференциация субъектов РФ практически не учитывается в процессе налогового регулирования деятельности субъектов малого бизнеса. На наш взгляд, эти различия должны учитываться корректирующими коэффициентами, которые показывают степень влияния того или иного условия на результат предпринимательской деятельности, облагаемой единым налогом на вмененный доход. Несоразмерность налоговой нагрузки по регионам объясняется различиями в порядке и методике определения корректирующего коэффициента К-2, которые разрабатываются местными органами власти. Разнородность используемых подходов, главным образом не учитывающих все многообразие влияющих факторов, не могут обеспечить не только тождество вмененного и фактического дохода, но и сопоставимость налоговой нагрузки для предпринимателей в различных субъектах РФ.

Исходя из выше изложенного, нами предлагается ввести альтернативный подход, при котором значения коэффициента К-2 устанавливались бы пропорционально показателю рентабельности, достигая максимального значения, равного 1 для тех субъектов предпринимательской деятельности, которые имеют наибольшую рентабельность. Именно рентабельность является главным показателем деятельности предприятий, отражающим результат влияния всех возможных факторов и условий ведения бизнеса. Применение такой методики возможно для большей части регионов РФ, поскольку рентабельность является 
наиболее часто анализируемым показателем, достаточно прозрачно определяется на основании бухгалтерской отчетности и, по существу, лежит в основе всех используемых подходов. Унификация способов исчисления корректирующего коэффициента базовой доходности и порядка детализации видов экономической деятельности даст возможность сопоставлять значения К-2 и сравнивать налоговое бремя для фирм, осуществляющих одни и те же виды деятельности в разных районах России.
На наш взгляд, реализация предложенных выше комплекса мер, успешно используемых в индустриальных странах, поможет совершенствовать систему и режимы налогообложения малого бизнеса, распределить налоговую нагрузку между субъектами предпринимательства соразмерно масштабу их финансово-экономической деятельности, стимулировать рост и развитие малых предприятий, улучшить налоговое администрирование и повысить налоговые доходы консолидированного бюджета РФ.

\section{Библиография}

1. Акимов А. А. Анализ практики налогообложения малого бизнеса в России. // Все для бухгалтера. 2007.- № 4- С.2333.

2. Александров И. М. Налоговые системы России и зарубежных стран.- М., 2007. $225 \mathrm{c}$.

3. Борисов В. Нам нужен активный, конкурентоспособный малый бизнес // Человек и труд.- 2008.- № 3.- C.45.50.

4. рибкова Н. Б. Опыт налогового регулирования в зарубежных странах и возможности его использования в России. // Налоговая политика и практика. 2005.№ 7.- С.16-20.

5. Данные официального сайта Общероссийской общественной органи- зации «Опора России» www. opora. ru.

6. Малый бизнес: учебное пособие / кол. авторов: под ред. В. Я. Горфинкеля.М.: КНОРУС, 2009. 336 с.

7. Мельник А. М. Малый бизнес и региональное развитие в индустриальных странах.- М.; 2007. 342c.

8. Михайлов Е. Система местного налогообложения США. США: ЭПИ; 2005. 120с.

9. Мусаева Х. М. Налоговые системы зарубежных стран. Махачкала: ИПЦ ДГУ; 2011. 242 c.

10. Structures of the Taxation Systems in the European Union, Data 1995-2005 / Theme Economy and Finance.- European Commission Edition, 2007.- 417 pp.

11. Explanatory Notes to the OECD Tax Database, 2005. www.oecd.org/dataoecd

\section{References (transliterated)}

1. Akimov A.A. Analiz praktiki nalogooblozheniya malogo biznesa $\mathrm{v}$ Rossii. // Vse dlya bukhgaltera. 2007.№ 4- S.23-33.

2. Aleksandrov I. M. Nalogovye sistemy Rossii i zarubezhnykh stran.- M., 2007. 225 s.
3. Borisov V. Nam nuzhen aktivnyi, konkurentosposobnyi malyi biznes // Chelovek i trud.- 2008.- № 3.- S.45.50.

4. Gribkova N. B. Opyt nalogovogo regulirovaniya $\mathrm{v}$ zarubezhnykh stranakh i vozmozhnosti ego ispol'zovaniya v Rossii. 
DOI: $10.7256 / 1812-8688.2013 .12 .4059$

При цитировании этой статьи сноска на doi обязательна

Налоговые системы зарубежных стран

//Nalogovaya politika i praktika. 2005.№ 7.- S.16-20.

5. Dannye ofitsial'nogo saita

Obshcherossiiskoi obshchestvennoi organizatsii «Opora Rossii» www. opora. ru.

6. Malyi biznes: uchebnoe posobie / kol. avtorov: pod red. V. Ya. Gorfinkelya.- M.: KNORUS, 2009. $336 \mathrm{~s}$.

7. Mel'nik A. M. Malyi biznes i regional'noe razvitie v industrial'nykh stranakh. - M.; 2007. 342s.
8. Mikhailov E. Sistema mestnogo nalogooblozheniya SShA. SShA: EPI; 2005. 120s.

9. Musaeva Kh.M. Nalogovye sistemy zarubezhnykh stran. Makhachkala: IPTs DGU; 2011. $242 \mathrm{~s}$.

10. Structures of the Taxation Systems in the European Union, Data 1995-2005 / Theme Economy and Finance.- European Commission Edition, 2007.-417 pp.

11. Explanatory Notes to the OECD Tax Database, 2005. www.oecd.org/dataoecd 